KAMITA, João Masao. Sobre a Praça das Artes. Thésis, Rio de Janeiro, v. 5, n. 9, p. 75-84, nov. 2020

data de submissão: $22 / 09 / 2020$ data de aceite: $12 / 11 / 2020$

\section{Sobre a Praça das Artes João Masao Kamita}

João Masao KAMITA é Doutor em Arquitetura e Urbanismo, Professor do Programa de Pos-Graduação em Arquitetura e Urbanismo/PUC-Rio e do Programa de Pós-Graduaçao em Historia Social da Cultura/PUC-Rio; masao@puc-rio.br

\section{Resumo}

Este artigo procura analisar o partido arquitetonico e urbanismo do projeto da Praça das Artes, construido entre 2006 e 2012, na cidade de Sao Paulo, pelo escritorio Brasil Arquitetura. Sua hipotese principal é a de que o projeto emite uma nota destoante em relaçao ao modelo brutalista vigente e, portanto, se aproxima de questoes contemporaneas da arquitetura.

Palavras-chave: Praça das Artes, Brasil Arquitetura, projeto.

\section{Abstract}

This article analyzes the architectural and urban design concept of the Praça das Artes project, built between 2006 and 2012, in the city of Sao Paulo, by the Brasil Arquitetura office. Its main hypothesis is that the project gives a different note in relation to the current brutalist model and, therefore, approaches contemporary questions of architecture.

Keywords: Praça das Artes, Brasil Arquitetura, design.

\section{Resumen}

Este artículo analiza el concepto de diseño arquitectónico y urbano del proyecto Praça das Artes, construido entre 2006 y 2012, en la ciudad de Sao Paulo, por la oficina de Brasil Arquitetura. Su principal hipótesis es que el proyecto da una nota diferente en relación al modelo brutalista actual y, por tanto, aborda cuestiones contemporáneas de la arquitectura.

Palabras clave: Praça das Artes, Brasil Arquitetura, proyecto.

\section{Sobre a Praça das Artes}

São Paulo SP, 2006-2012

\section{Brasil Arquitetura}

(Marcelo Ferraz, Francisco Fanucci e Marcos Cartum)

A Praça das Artes (Figura 1) tem um modo de presença incomum. Uma forma expressiva que tira proveito do dispersivo, das justaposições abruptas, do aproveitamento parasitário dos espaços disponíveis. E o faz de maneira intencionalmente enfática, anunciado diretamente pela sua materialidade inesperada em aparente desacordo com a disposição lógica dos elementos da construção.

Uma articulação meio labiríntica, meio informe, logo, uma forma flagrantemente urbana. 


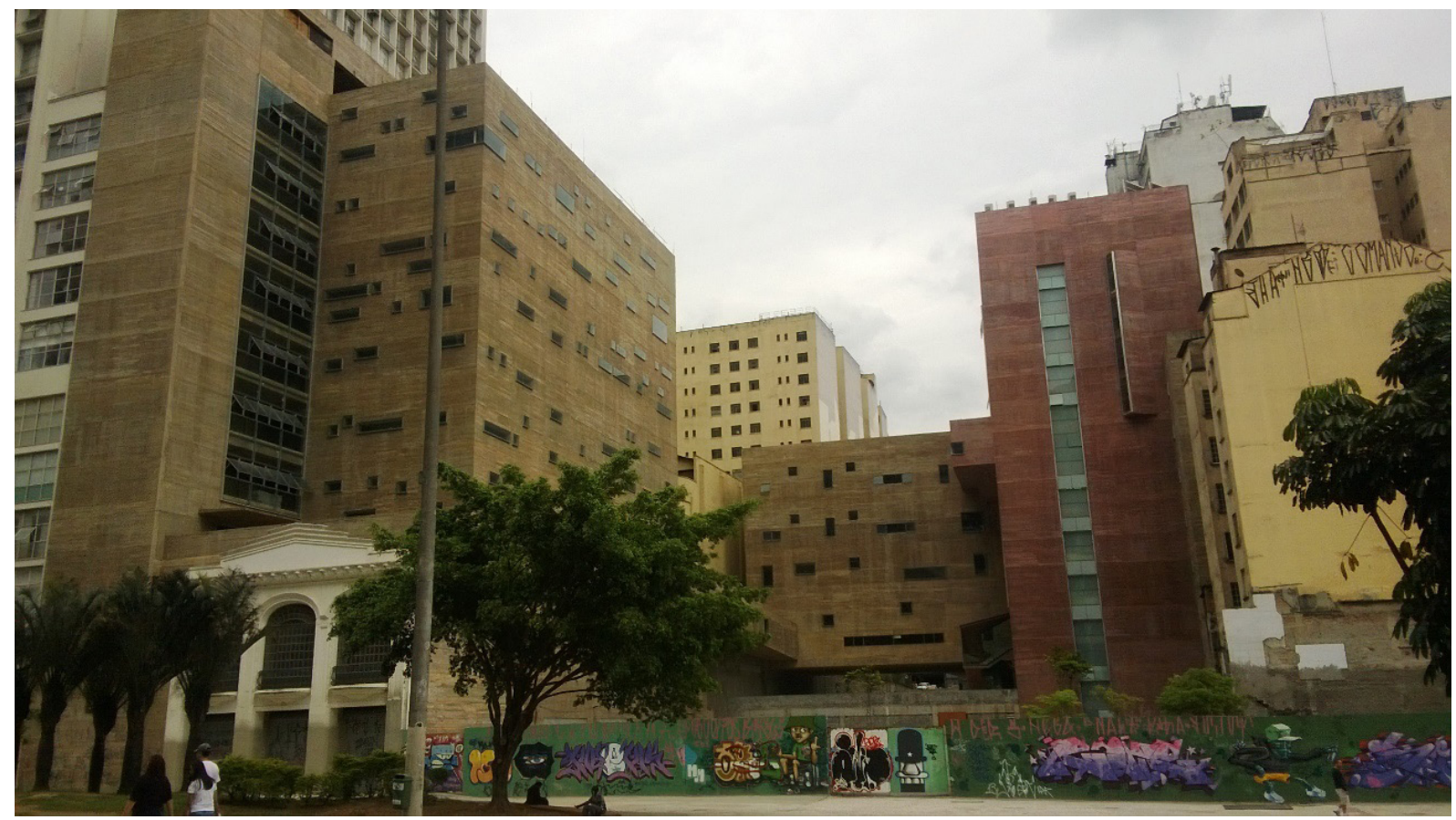

Figura 01

Praça das Artes - Vista da Rua Formosa

Fonte: Masao Kamita

Concebido como um complemento ao Teatro Municipal, a Praça das Artes incorpora o conservatório de música, mas expande exponencialmente o programa ao incluir escola de música, escola de dança e centro de documentação musical, bem como as sedes dos corpos artísticos do teatro (orquestra, quartetos de cordas e corais).

O complexo da Praça das Artes tem na sua implantação (Figura 2) um dos pontos chave do projeto. Trata-se de uma ocupação do miolo de uma quadra, formado pela conjunção de vários lotes que se aglutinam e que tem saída para três das quatro ruas que a cercam (Rua Formosa que ladeia o Vale do Anhagabaú, a Avenida São João e a Rua Conselheiro Crispiniano). Trata-se de um lugar absolutamente central, tanto pela sua localização histórica onde praticamente a cidade de São Paulo surgiu, como por estar voltado para uma das áreas públicas mais conhecidas da cidade: o vale do Anhanbaú, entre os viadutos do Chá e Santa Ifigénia. Além do Teatro Municipal, com a praça Ramos de Azevedo coligada, a área concentra uma série de edificações destacadas: a sede da prefeitura, o edifício Conde de Prates de Giancarlo Palanti, o edifício dos Correios, o edifício Mirante do Vale de Zarzur e Kogan, o edifício Martinelli, o Mosteiro de São Bento, o edifício do BANESPA.

Apesar de sua situação impar, o local encontrava-se degradado, como de fato, todo o entorno. Lidar com 


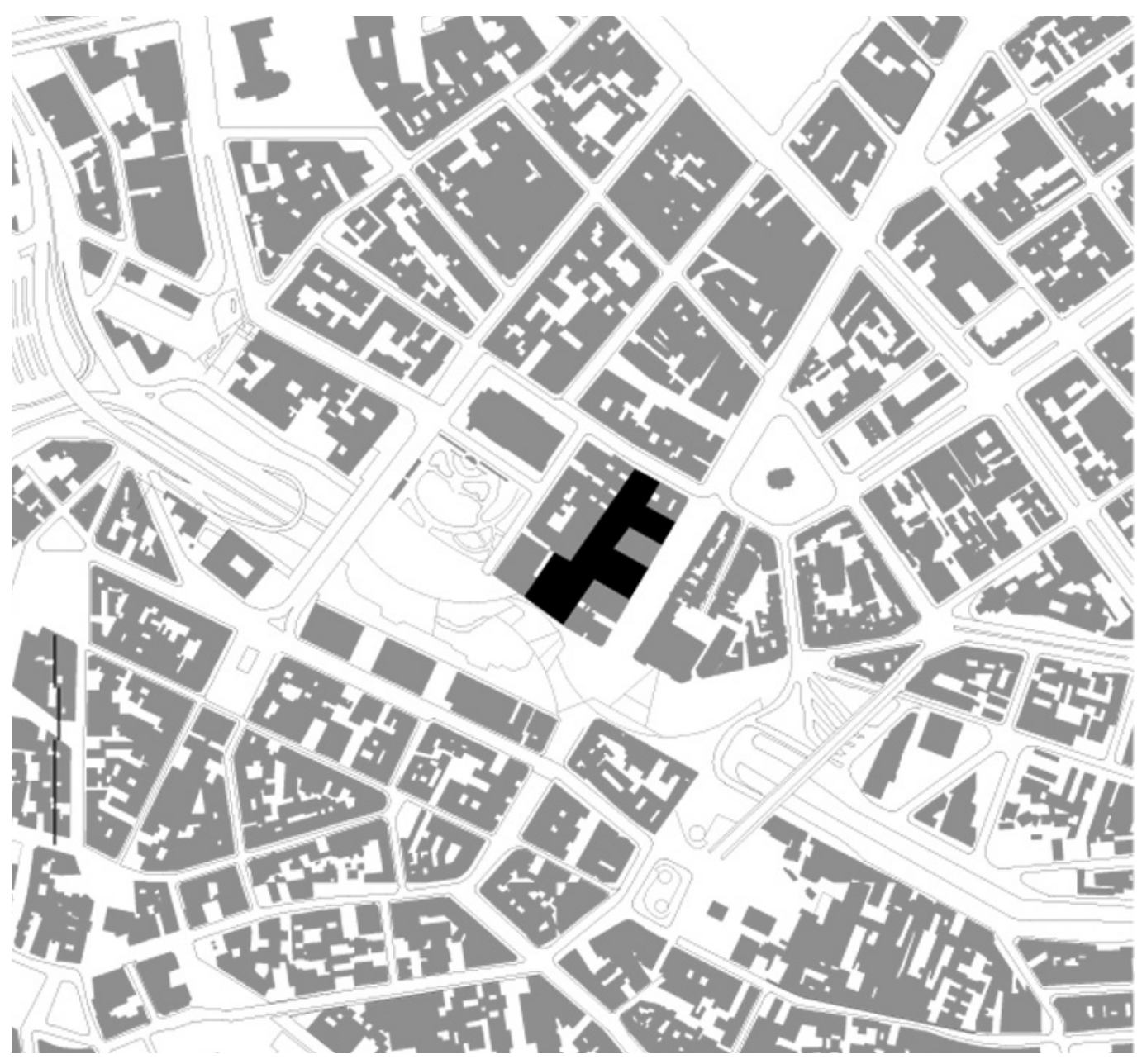

Figura 02

Praça das Artes - Implantação

Fonte: Brasil Arquitetura

essa espacialidade negativa, irregular, cercada de sobras e acumulações desregradas e comprimidas, enfim, encarar essa condensação de dificuldades buscando incorporá-las ao projeto revelou-se a principal decisão do projeto.

Conforme reconhecem os próprios autores, a compreensão da "natureza do lugar" foi o fato decisivo para a formulação do partido da Praça.

Há projetos de arquitetura que se impõem soberanos em grandes espaços livres, situações aprazíveis e visíveis à distância. Há outros projetos que precisam se acomodar a situações adversas, espaços mínimos, nesgas de terrenos comprimidos por construções existentes, em que os parâmetros para seu desenvolvimento são ditados por tais singularidades. O caso da Praça das Artes se enquadra entre estes últimos. (VITRUVIUS/Projetos 151/03)

Mas o desenho da cidade não é fato casual, aleatório, arbitrário, muito ao contrário, é a resultante implacá- 
vel de um processo social de ocupação, cujos fatores econômicos e políticos são determinantes na sua produção. A situação urbana do "lote" é o ponto de partida para compreensão desse processo visceral de crescimento e densificação do centro histórico da cidade de São Paulo. Na realidade, trata-se de um conjunto de sobras de lotes que formam o miolo da quadra, o locus do projeto. O "vazio" gerado pode ser associado ao "terrain vague" de Sola-Morales, ou seja, uma negatividade significativa, uma condição vaga mas flutuante, cuja ausência contém traços de várias outras presenças, cujos fragmentos de memória encontram-se dispersos no lugar. Como este, há um sem número de outras "reservas" sob a espreita da ação predatória da especulação imobiliária.

"São lugares aparentemente esquecidos, onde parece predominar a memória do passado sobre o presente. São lugares obsoletos nos que somente certos valores residuais parecem se manter apesar de sua completa desafeição da atividade da cidade. São, em definitivo, lugares externos, estranhos, que ficam fora dos circuitos, das estruturas produtivas.

(...) Em definitivo, lugares estranhos ao sistema urbano, exteriores mentais no interior físico da cidade que aparecem como contraimagem da mesma, tanto no sentido de sua crítica como no sentido de sua possível alternativa." (SOLA-MORALES, 2002)

Contudo, a defesa poética do terrain vague da parte de Sola-Morales, enquanto forma crítica ao ímpeto

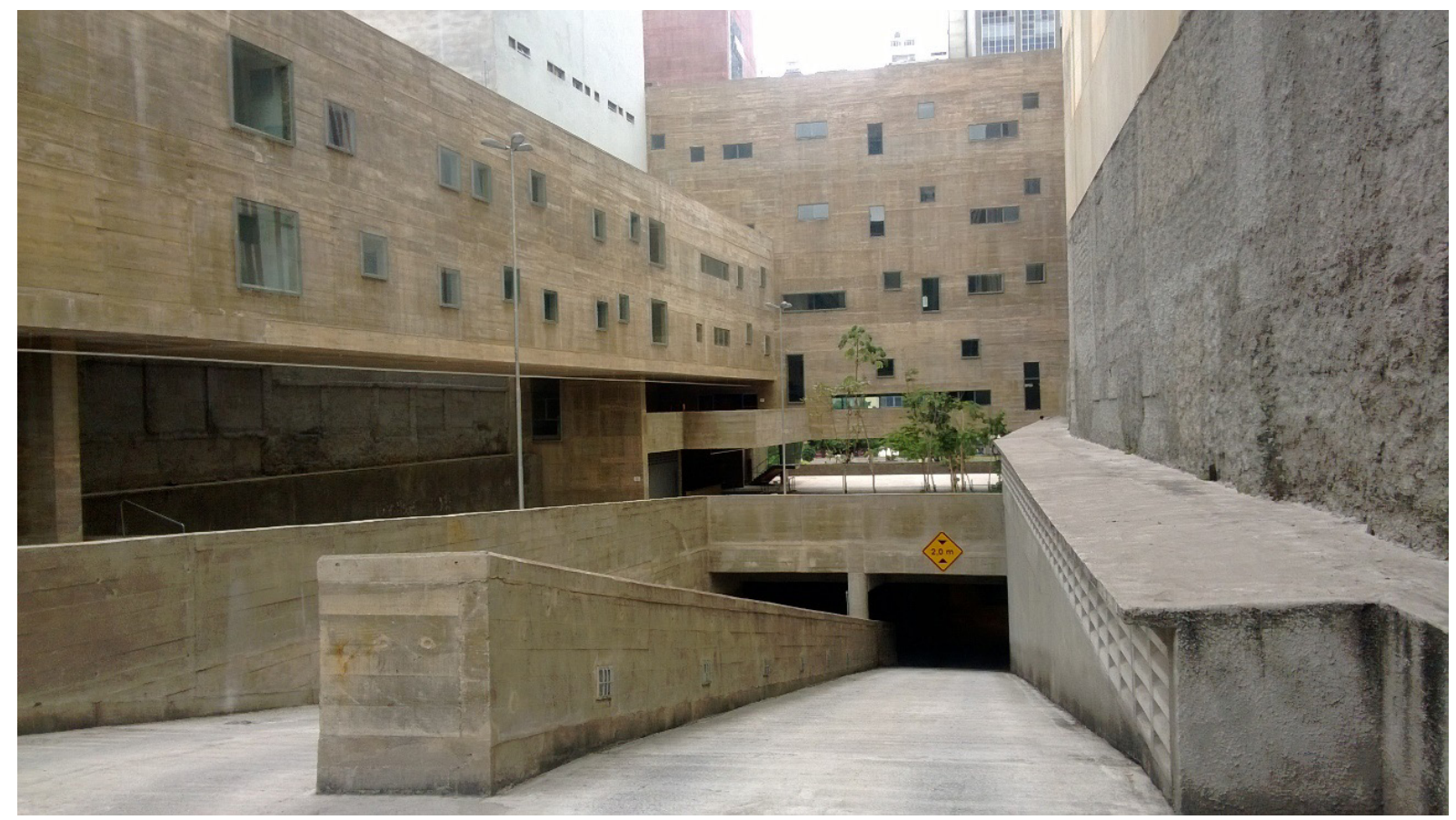

Figura 03

Praça das Artes - Vista do interior do lote

Fonte: Masao Kamita 
produtivista da cidade, coloca um paradoxo à arquitetura, na medida em que ela se apresenta como o agente por excelência que ocupa, organiza e reintroduz uma razão de ser àquilo que se encontrava sem destino. Sua divisa é: preencher o vazio. Mas ao optar por uma implantação esgueirante, de modo a manter traços do abandono existente, o projeto do Brasil Arquitetura resolve de maneira inteligente o paradoxo, justamente, ao optar por não eliminar a negatividade, senão potencializa-la.

Contra a tendência de subdivisão tradicional do lote urbano em porções individuais regulares, gerando construções coladas umas as outras, com frente para a via pública e sobras irregulares aos fundos - modelo por excelência da quadra fechada - o projeto da Praça das Artes transforma aquilo que comumente seria residual em princípio ativo do espaço, assim, desafia o padrão histórico do desenho das cidades que relaciona arquitetura e malha urbana. Ocupar as entranhas da quadra (Figura 3) para daí facultar o acesso e o usufruto público, eis o princípio definidor do partido. Esgueirando-se pelas sobras negativas dos terrenos, o complexo aparece, desaparece e reaparece para a rua, contorna, envolve e percorre lugares imprevistos. Nesse verdadeiro ato antropofágico, incorpora duas construções existentes e abandonadas: o Cine Cairo e o antigo Conservatório Dramático Musical de São Paulo (Figura 4). De fato, efetua um verdadeiro atravessamento da quadra, quebrando as barreiras físicas e ideológicas da propriedade privada. O eixo dominante é o que corre no sentido do Vale do Anhangabaú-Rua ConseIheiro Crispiniano, por onde o espaço escoa sem impedimentos no nível térreo. Do mesmo modo, essa abertura ocorre no acesso da Avenida São João, no qual o volume suspenso libera totalmente o acesso, constituindo-se assim numa verdadeira praça coberta.

Os blocos programáticos são distribuídos ao longo desses 3 eixos, voltando-se para a rua Formosa e para a Avenida São João. Na intersecção localiza-se a torre administrativa e de apoio, ponto de referência junto com o pavilhão das escolas e restaurante, dos quais partem os "tentáculos" programáticos e volumétricos do edifício dos corpos artísticos, do centro de documentação e das salas de ensaio. Ligações diretas são efetuadas por tuneis passarelas: a que liga o restaurante ao aos corpos artísticos, o que conecta a torre ao pavilhão e o que segue rumo à Rua ConseIheiro Crispiniano (que é um túnel-pavimento para ensaios). Esses três elementos são espécies de vetores direcionais do atravessamento do espaço. 


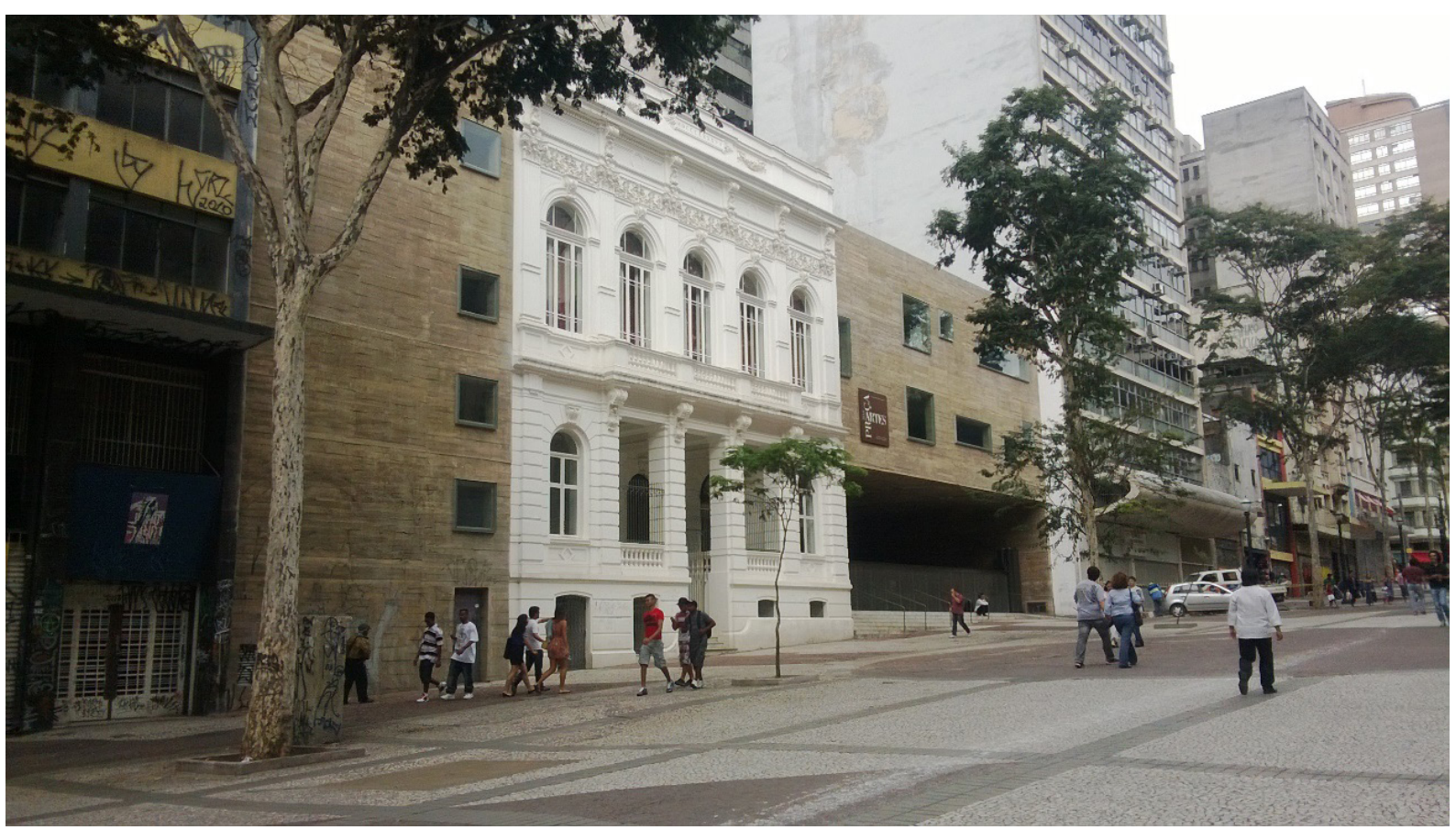

Figura 04

Praça das Artes - Vista da Avenida São João com o Antigo Conservatório Dramático e Musical

Fonte: Masao Kamita

A Praça das Artes, em um primeiro momento, afirma um modo de ser que contraria as construções existentes com sua disposição intrusa, quase parasitária pelos interstícios do quarteirão. O padrão do edifício isolado com volumetria unitária e monolítica típicos do modernismo ou o padrão eclético com base, corpo e coroamento dispostos a partir de eixos de simetria (complementado pelas colunas e ornatos) parecem avançados no tempo em relação ao primitivismo do conjunto da Praça das Artes.

Por isso, a meu ver a opção de atribuir ao célebre concreto aparente brutalista, ao invés da secção rija, dura e cinzenta, a consistência mole e a tonalidade ocre da "taipa", com a marca dos pranchões de madeira. Daí, a necessidade de passar a impressão de um plano não subdividido em pavimentos, algo que normalmente ocorre pela marcação rítmica dada por lajes, parapeitos e fenestração, reveladores do "empilhamento" de camadas horizontais de espaço. Na Praça das Artes, a sensação deveria ser de um muro único, como os das igrejas coloniais. Daí o misto de aparência musgosa e terrosa, o cinza do concreto aparente o ocre da argila. Assim, vão regulares surgem nos planos de fechamento, de fato como pequenas perfurações num todo cheio e consistente a partir de uma rítmica aleatória. 
A forma contrastante com que a Praça das Artes se mostra se deve a sua aparência arcaica, tanto em relação aos palacetes ecléticos do início do século como antigo Cine Cairo e o antigo Conservatório Dramático Musical, quanto dos ilustres vizinhos modernistas: o

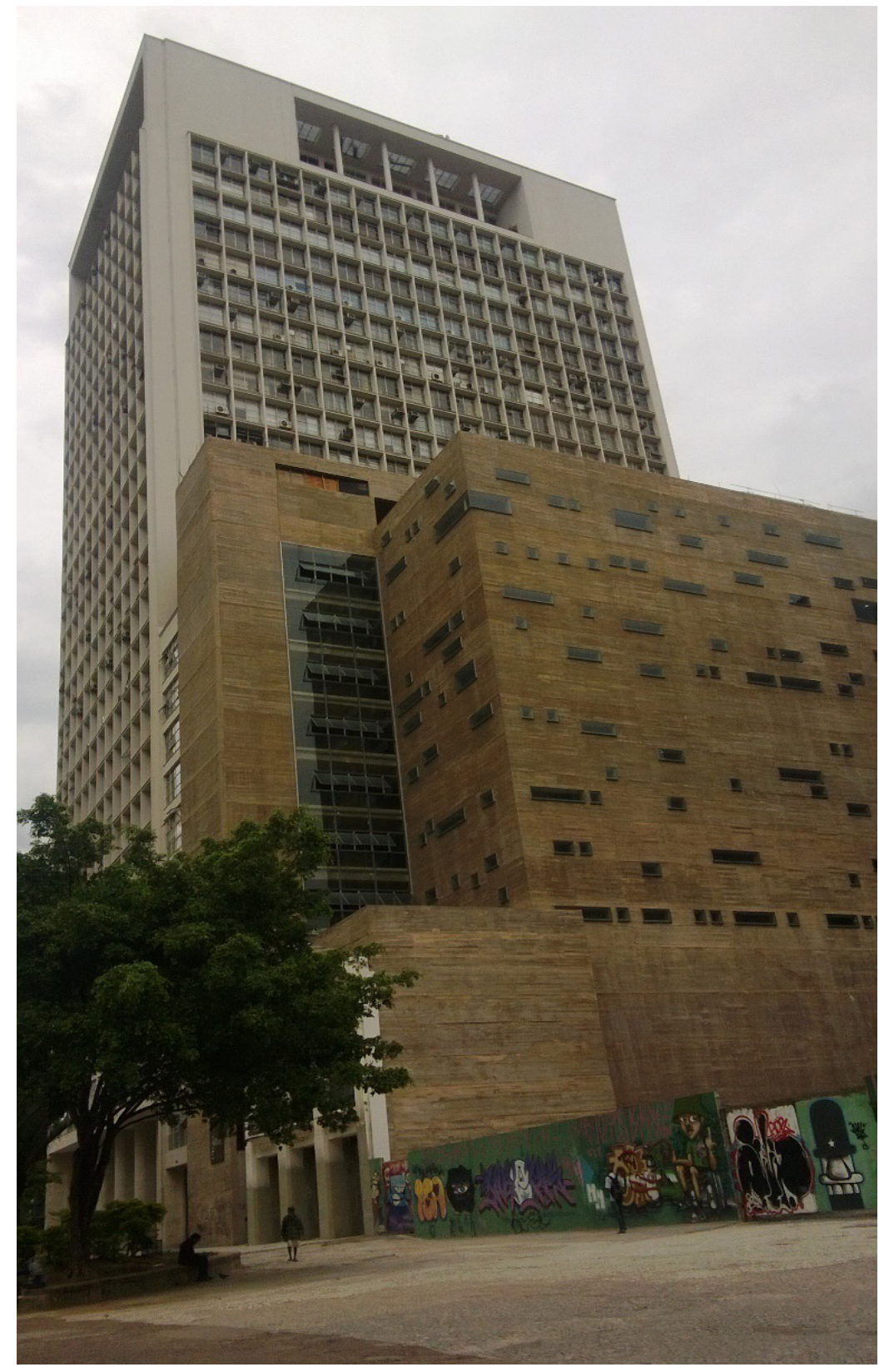

Figura 05

Praça das Artes - Vista da Rua Formosa junto ao Edifício CBI Fonte: Masao Kamita

edifício CBI Esplanada na rua Formosa (Figura 05), projeto de Lucjan Korngold, o edifício Seguradoras, na Av. São João, de Oscar Niemeyer. As fachadas antigas foram não apenas restauradas, mas purificadas pela pintura branca, o que radicaliza a sua contraposição 
com o concreto aparente dos blocos ao redor, resultando em puros planos ecléticos. Mais exatamente um écran superficial. Já a diferença com as torres modernistas se revela no contraste entre valores opostos: transparência e opacidade.

A presença marcante da Praça das Artes se dá de um modo paradoxal: é uma forma sem forma, uma arquitetura anterior à "era da arquitetura", uma materialidade pretérita, primitivista mesmo. Curiosamente essa condição pré-construtiva é o que faculta o inesperado entendimento com a condição desgastada, deteriorada mesmo das banais edificações limítrofes. E aí sua lógica de ocupação e tratamento de superfície se demonstrar inclusiva e adaptativa ao incorporar as incongruências do lugar, não rompendo, portanto, com o contexto no qual se insere. Nesse sentido, o projeto se mostra menos projeto de edificação do que projeto de paisagem.

Não há como não atentar para esse lado expressivo do projeto, o estranhamento pela introdução de tais elementos incongruentes num meio de densa urbanização. Não há como não se remeter, quase num exercício surreal de rememoração de um tempo perdido, das primeiras ocupações da modesta vila de São Paulo da Piratininga a partir do triângulo religioso (Sé, São Bento e São Francisco) original e a expansão pelo eixo da Avenida São João atravessando o vale do Anhangabaú, com seu terreno alagadiço e com suas chácaras e plantações, com os primeiros calçamentos de terra batida e pedra e construções coloniais de paredes caiadas e grandes beirais. Não há como não atentar para as condições rústicas da primeira urbanização quando a construção e a paisagem bruta ainda se encaravam de igual.

Esse jogo inesperado do moderno e do arcaico, essa simultaneidade de temporalidades distintas, deve muito à poética de Lina Bo Bardi, cujo estranhamento era estratégia assumida para iluminar e abrir perspectivas inéditas. Esse procedimento estético não é estranho a alguém como Marcelo Ferraz, um dos autores do projeto, que trabalhou durante muitos anos com a arquiteta. Há todo um conjunto de projetos do escritório Brasil Arquitetura em que se percebe o transito entre o atual e o vernacular, ou mesmo a tradição construtiva popular, em especial casos de requalificação de estruturas existente. No entanto, sempre no limite de certo ecletismo construtivo. O que surpreende na Praça das Artes é o rigor e a radicalidade do projeto, o que me parece lhe confere certa vitalidade contemporânea. 
Nesse ponto, o tema é inevitável: a questão da herança e da influência. Como o herdeiro assume, recolhe e propaga um legado? Como não se tornar subserviente, verdadeiramente sufocado pela força intimidadora da obra anterior a que se pretende ser fiel?

Tais são os dilemas da "Angustia da Influência", célebre livro de Harold Bloom (1991) que trata da influência poética e do diálogo verdadeiramente bélico entre poetas, quando um poeta posterior distorce a leitura do poeta precursor, efetuando aquilo que o autor chama uma "má leitura" do texto original. Ou seja, efetuando um salto criativo que faz com que a influência deixe de ser simplesmente "uma transferência de personalidades" para se tornar um "poeta forte" com personalidade própria. Bloom esboça alguns "movimentos revisionários" de como o poeta se desvia da influência de outro.

- Desvio corretivo, quando é preciso encontrar na obra anterior um defeito que não está nela e daí corrigi-la;

- Completude por antítese, quando o poeta posterior isola um fragmento da obra anterior, retendo-o a seu favor para leva-la para outro caminho, como se o precursor não tivesse ido longe o bastante;

- Descontinuidade, quando opera o esvaziamento do antecessor, que é claro é sempre relativo;

- Despersonalização generalizante, quando atribui à obra fundadora o caráter de representação de certo estado geral, relativizando, portanto, o valor unitário do autor original;

- Retorno, quando já no final de sua carreira o poeta que vem depois se mostra de novo aberto à obra do precursor de tal modo que pareceria que o poema do precursor teria sido escrito pelo da posteridade.

Estas categorias evidentemente não esgotam as possibilidades de debate poético entre obras e artistas, mas servem de começo para se avaliar a fundo as possibilidades de produtivas "desleituras criticas". Em algum momento, nossos grandes heróis precisam ser questionados. 


\section{Referências}

BLOON, Harold. A angustia da influência: uma teoria da poesia. Rio de Janeiro, Imago, 1991

SOLÀ-MORALES, Ignasi de. Territórios. Barcelona, Gustavo Gili, 2002.

VITRUVIUS, Portal. Praça das Artes / São Paulo SP, 2006-2012. Brasil Arquitetura e Secretaria Municipal de Cultura [Marcelo Ferraz, Francisco Fanucci e Marcos Cartum]. Secção Projetos, 151.03ano 13, jul. 2013.

https://www.vitruvius.com.br/revistas/read/projetos/13.151/4820 